\title{
Efeitos da Exposição Ocupacional ao Mercúrio em Trabalhadores de uma Indústria de Lâmpadas Elétricas Localizada em Santo Amaro, São Paulo, Brasil
}

\author{
Effects of Occupational Exposure to Mercury in Workers at a Light Bulb \\ Factory in Santo Amaro, São Paulo, Brazil
}

\author{
Cecília Zavariz ${ }^{1}$ \\ Débora Miriam R. Glina²
}

ZAVARIZ, C. \& GLINA, D. M. R. Effects of Occupational Exposure to Mercury in Workers at a Light Bulb Factory in Santo Amaro, São Paulo, Brazil. Cad. Saúde Públ., Rio de Janeiro, 9 (2): 117-129, Apr/Jun, 1993.

The aim of this research was to study metallic mercury poisoning in workers at a light bulb factory in Santo Amaro, São Paulo (Brazil). Visits were made to the factory to check both the work environment and the working conditions. Meetings with the workers took place in order to better understand the production process and how working conditions affect their health. Of the 91 workers investigated, 77 (84.62\%) were chronically poisoned. Among chronically poisoned workers, $76(98.70 \%)$ displayed neuropsychological alterations, $69(75.82 \%)$ suffered from neurological impairments, $62(68.13 \%)$ showed pathological findings under clinical examination, and 59 (63.96\%) displayed psychiatric disorders.

Key words: Occupational Exposure; Adverse Effects; Mercury; Industrial Toxicology

\section{INTRODUÇÃO}

O mercúrio é utilizado em um grande número de processos industriais, entre eles a produção de lâmpadas fluorescentes. A concentração de mercúrio no ar altera-se de acordo com a temperatura, sendo que a evaporação é maior quanto mais elevada for esta última.

A absorção do vapor de mercúrio se dá principalmente por via pulmonar, através da inalação. Segundo Foá (1986), a percentagem de retenção nos pulmões varia de 74 a $80 \%$.

O mercúrio é levado dos pulmões pelo sangue e se distribui no organismo, acumulando-se nos rins, sistema nervoso central, fígado, medula óssea, vias aéreas superiores, pele, parede

\footnotetext{
${ }^{1}$ Departamento de Saúde Ambiental da Faculdade de Saúde Pública da Universidade de São Paulo. Av. Dr. Arnaldo 715, São Paulo, SP, 01255-000, Brasil.

${ }^{2}$ Departamento de Psicologia do Trabalho das

Faculdades São Marcos. Rua Clóvis Bueno de Azevedo 176, São Paulo, SP, 04262-100, Brasil.
}

intestinal, glândulas salivares, coração, músculos e placenta. A eliminação de mercúrio no organismo é feita principalmente através dos rins.

Segundo Foá (1985), existe uma variabilidade individual significativa nos grupos ocupacionalmente expostos. A correlação entre exposição diária (avaliada pela concentração de mercúrio ambiental) e mercúrio na urina (e também no sangue), em um mesmo dia, é muito pobre e, em alguns casos, inexistente, o que prova que a concentração na urina, assim como no sangue, no fim da jornada de trabalho, não reflete a exposição ocorrida naquele dia.

O mercúrio em baixas concentrações pode levar a uma intoxicação crônica. O quadro clássico atinge o aparelho gastrintestinal, o sistema nervoso e as funções psíquicas, cujas alterações variam de quadros leves a muito graves.

$\mathrm{O}$ quadro gastrintestinal manifesta-se por lesões orais, do estômago, intestinos e fígado. A gengivite é o distúrbio mais comumente encon- 
trado. Também ocorrem queixas de desagradável gosto amargo ou metálico na boca, sialorréia, ulcerações orais e amolecimento dos dentes. É comum a ocorrência de faringite inespecífica. Outras manifestações encontradas são a gastrite e a gastroduodenite (Encyclopaedia of Occupational Health and Safety, 1989).

$\mathrm{O}$ quadro neurológico pode manifestar-se por tremores, alterações das sensibilidades dolorosa, térmica e tátil, alteração dos reflexos, da coordenação motora e até parkinsonismo.

O quadro psíquico constitui-se em uma constelação de alterações de personalidade que Foá e Caimi (1981) denominaram de eretismo psíquico. Estes autores referem que os sinais típicos e precoces da intoxicação crônica por mercúrio são irritabilidade, alteração da sociabilidade, insônia, ansiedade, timidez, labilidade emocional e, nos casos mais graves, diminuição da atenção e da memória, até chegar a um processo de despersonalização geral.

Em um estudo com pacientes expostos ao mercúrio metálico, Vroom \& Greer (1972) encontraram dados sobre ansiedade e depressão em todos os casos, além de insônia, irritabilidade, esquecimento, dificuldade de concentração, insegurança e diminuição das habilidades sociais.

Para Alonso (1972), as primeiras alterações psíquicas que aparecem nas intoxicações crônicas integram uma síndrome neurasteniforme cujos elementos mais significativos são a astenia e a irritabilidade, além de cefaléia, vertigens, diminuição da memória, entre outros.

Caso persista a exposição ao tóxico, o quadro evolui para uma psicossíndrome orgânica. Às vezes, tal síndrome manifesta-se por uma perda de iniciativa e espontaneidade, bem como por dificuldades de lidar com situações que transcendam o imediato e o cotidiano.

Angotzi et al. (1980) utilizaram os seguintes procedimentos para a avaliação dos aparelhos gastrintestinal, cardiovascular, urinário, otoneurológico e visual:

- Aparelho gastrintestinal: anamnese, exame clínico da cavidade oral e exames laboratoriais (bilirrubinas, transaminases, proteínas totais e eletroforese de proteínas séricas);

- Aparelho cardiovascular: anamnese, questionário específico para doenças cardiovascula- res, exame físico (auscuta cardíaca e determinação da pressão arterial), dosagem de colesterol e de triglicerídeos e eletrocardiograma;

- Aparelho urinário: dosagem de proteinúria total;

- Aparelho otoneurológico: anamnese, exame audiométrico tonal e vocal, e impedanciometria;

- Aparelho visual: eletronistagmografia.

Hartman (1988) salienta a importância de se montar uma bateria de testes com solidez psicométrica e bem validada e destes escolher testes que enfatizem áreas do funcionamento neuropsicológico correlacionadas com as alterações provocadas pelo agente tóxico. A bateria deve compreender uma grande gama de funções cognitivas, afetivas e neurocomportamentais. $\mathrm{O}$ autor, após rever as recomendações de testes de vários neuropsicólogos, percebeu a existência de sugestões comuns a todos. Medidas de velocidade motora,coordenação motora fina, destreza manual, memória e eficiência cognitiva são sugeridas por todos. Algumas baterias, mas não todas, incluem testes de personalidade como parte do exame. E, finalmente, como as habilidades não-verbais tendem a ser as mais afetadas pelos neurotóxicos, a bateria deve enfatizar tais funções.

Hänninen (1982) concluiu que as anormalidades neuropsicológicas induzidas por mercúrio compunham três grandes grupos: 1) anormalidades no sistema motor (por exemplo, tremor fino); 2) danos intelectuais (deterioração progressiva da memória, concentração e raciocínio lógico); e 3) dificuldades emocionais.

Piikivi et al. (1984) utilizaram um teste de inteligência verbal (similarities - Wechsler Adult Inteligence Scale) e outro para a coordenação mão/olho (Santa Ana Dexterity Test). Os déficits mais significativos estiveram relacionados à inteligência verbal e à memória.

A seguir, serão expostas as bases teóricas de duas propostas a respeito do trabalho com grupos de trabalhadores.

O modelo operário italiano, segundo Oddone et al. (1986), foi originalmente formulado por um grupo de operários e profissionais em Turim, no final dos anos 60 , sendo um método de produção de conhecimento para a ação operária.

Segundo Laurell \& Noriega (1989), a con- 
cepção teórica deste modelo é a visão materialista histórica do trabalho. A fábrica é abordada como um todo, ocorrendo, em um primeiro momento, uma avaliação subjetiva por um grupo homogêneo de trabalhadores. Em uma primeira etapa, os elementos do ambiente de trabalho nocivos à saúde são colocados pelos trabalhadores em quatro grandes grupos.

Segundo Oddone et al. (1986), o primeiro grupo (verde) compreende os fatores presentes também no ambiente em que o homem vive fora do trabalho: luz, barulho, temperatura, ventilação e umidade. O segundo grupo (vermelho) compreende os fatores característicos do ambiente de trabalho: poeiras, vapores, fumaças. O terceiro grupo (amarelo) compreende um fator: a atividade muscular ou trabalho físico. $\mathrm{O}$ quarto grupo (azul) compreende todas as condições que possam determinar efeitos estressantes: monotonia, repetitividade, ritmos excessivos, ocupação do tempo, posições incômodas, ansiedade, responsabilidade, frustrações e todas as outras causas de efeitos estressantes diferentes do trabalho físico.

O modelo é suportado por quatro critérios: 1) grupo homogêneo, que é o grupo de operários que compartilham as mesmas condições de trabalho e têm laços orgânicos entre si; 2) não-delegação, isto é, os sujeitos são os operários que ali trabalham e não os seus representantes ou os técnicos; 3) experiência ou subjetividade operária, que parte da observação espontânea feita pelos operários das condições de trabalho e seus efeitos na saúde. Esta observação é sistematizada e convertida em patrimônio comum através da colocação nos quatro grupos de risco; 4) validação consensual, isto é, só são registradas as observações que o grupo homogêneo, em seu conjunto, reconhece como corretas e verídicas.

Em uma segunda etapa ocorre a verificação, com medições e registros bioestatísticos, dos fatos revelados na pesquisa coletiva para que se possa quantificá-los. Os operários dizem o que, onde e quando medir. Com essas informações, elabora-se o mapa de risco (representação gráfica do processo de trabalho, com seus riscos e danos à saúde).

Em uma terceira etapa, o grupo, com base no conhecimento gerado e moldado no mapa de risco, constrói sua plataforma de reivindicações através da validação consensual.

Tomando por base este modelo, mas adaptando-o às suas necessidades práticas, Laurell \& Noriega (1989) elaboraram uma proposta de investigação. Tal proposta é pautada pela formulação teórica das relações entre processo de trabalho, cargas de trabalho (elementos do processo de trabalho que interatuam dinamicamente entre si e com o corpo do trabalhador, gerando processos de adaptação) e desgaste (perda da capacidade potencial e/ou efetiva, corporal e/ou psíquica).

Em um primeiro momento são estabelecidos os cinco grupos de risco. O primeiro grupo diz respeito às cargas físicas (temperatura, umidade, ruído, iluminação, etc.). Através de perguntas, determina-se se elas constituem problemas, como estes são gerados, suas intensidade e duração aproximadas, os lugares mais críticos, os trabalhadores mais expostos e a influência da organização e da divisão do trabalho sobre as mesmas. O segundo grupo compreende as cargas químicas (poeiras, fibras, fumaças, gases, vapores e líquidos). Pergunta-se sobre sua relação com objetos de trabalho, as condições das instalações, os instrumentos de trabalho, as concentrações aproximadas, os lugares mais críticos e os trabalhadores mais expostos. $\mathrm{O}$ terceiro grupo trata das cargas fisiológicas, relacionadas com as formas de uso do corpo (esforço físico, posições de trabalho). Através de perguntas, determina-se se estas existem, sua relação com objetos e instrumentos de trabalho, os trabalhadores mais expostos e a magnitude da exposição. O quarto grupo compreende as cargas psíquicas (situações de tensão prolongada e situações que impossibilitam o desenvolvimento e uso de uma capacidade psíquica): jornada (horário, pausas, turnos, alternância, folgas e horas-extras), periculosidade, freqüência de situações de emergência e responsabilidade pela solução das mesmas, ritmos, grau de atenção, grau de mobilidade dentro da fábrica, possibilidade de falar com companheiros de trabalho, possibilidade de trabalhar em grupo, supervisão, monotonia, repetitividade, entre outros. Pergunta-se sobre a intensidade e distribuição diferencial destas cargas entre os trabalhadores em função de suas tarefas. O quinto grupo diz respeito às cargas mecânicas, ou seja, elementos que causam traumatismo ("condições 
inseguras" decorrentes de medidas deficientes de segurança). Pergunta-se sobre sua relação com instrumentos e objetos de trabalho e sobre o grau de exposição dos diferentes grupos de trabalhadores.

Em uma segunda etapa são abordados os danos à saúde em função de cada um dos grupos de risco e, em uma terceira etapa, os resultados são complementados e confrontados com as informações geradas a partir de outras fontes.

\section{OBJETIVO}

O estudo teve como objetivo verificar os efeitos da exposição ao mercúrio metálico sobre a saúde.

\section{MATERIAL E MÉTODOS}

Foi realizado um estudo transversal compreendendo os seguintes aspectos:

\section{Visitas à Fábrica}

Realizadas a partir de agosto de 1990, estas visitas tinham por objetivo estudar o processo de trabalho. Verificou-se o fluxograma de trabalho, as jornadas de trabalho, as avaliações ambientais e médicas feitas pela empresa, a relação de trabalhadores e suas respectivas funções e as plantas da empresa, bem como o cumprimento das normas regulamentadoras previstas na Consolidação das Leis do Trabalho. As visitas só puderam ser realizadas através da fiscalização.

\section{Grupos de Trabalhadores}

Os grupos de trabalhadores reuniram-se no período de janeiro de 1991 a abril de 1992, quinzenalmente, no Centro de Referência em Saúde do Trabalhador (CRST) de Santo Amaro, e foram coordenados pelas autoras. Os objetivos do trabalho com os grupos foram:

1) instrumentar a análise científica da relação saúde-doença-trabalho;

2) propiciar o entendimento do processo de trabalho através da reconstrução do mesmo pelos relatos;

3) favorecer a conscientização dos trabalhadores sobre os riscos existentes e sobre os danos à saúde.

Para tanto, foram determinados os cinco grupos de risco sugeridos por Laurell \& Noriega (1989), a saber: cargas físicas, químicas, fisiológicas, psíquicas e mecânicas. Foram abordados os danos à saúde em função de cada um dos grupos de risco. Foi elaborado o mapa de risco, segundo o modelo operário italiano (Oddone et al., 1986).

\section{Atendimento aos Trabalhadores}

Do total de 641 trabalhadores da empresa, devido a dificuldades de liberação dos trabalhadores pela empresa para a realização de exames, somente parte deles procurou o CRST para avaliação, e o fizeram fora de seu horário de trabalho.

Noventa e um (91) trabalhadores tiveram suas avaliações concluídas até a realização deste trabalho. Portanto, os critérios de seleção da amostra foram o comparecimento ao CRST e a realização de todos os exames previstos.

Neste contexto, não foi possível realizar as avaliações em trabalhadores não-expostos da mesma empresa.

Os trabalhadores foram submetidos às seguintes avaliações no período de outubro de 1990 a junho de 1992:

\section{Clínica}

Foi elaborada uma ficha/prontuário para a coleta de dados e anotação da propedêutica. Constavam nesta ficha: identificação do paciente, história ocupacional anterior, histórico de afastamento do trabalho por acidente ou doença ocupacional, anamnese ocupacional, descrição da função,interrogatório sobre os vários aparelhos (gastrintestinal, cardiovascular, respiratório, renal, neurológico, psíquico, dérmico, visual e auditivo), indagação sobre o consumo de medicamentos, bebidas alcoólicas e drogas, tabagismo, anotações sobre o exame físico completo. Foi feita uma primeira avaliação da escrita do paciente. Os exames complementares solicitados 
foram os seguintes: a) aparelho gastrintestinal: exame de fezes, transaminase glutâmico-oxalacética (TGO) e transaminase glutâmico-pirúvica (TGP) (para todos os trabalhadores), fosfatase alcalina e endoscopia (para alguns trabalhadores, quando necessário); b) aparelho renal: urina I, uréia e creatinina (para todos os trabalhadores); c) aparelho cardiocirculatório: colesterol (para todos os trabalhadores que apresentaram hipertensão arterial); d) sistema hematopoiético: hemograma (para todos os trabalhadores); e) aparelho auditivo: audiometria tonal.

\section{Neurológica}

A avaliação neurológica consistiu na detecção de alterações da coordenação motora, das sensibilidades térmica, dolorosa e táctil, dos reflexos, dos movimentos involuntários, da força muscular, do equilíbrio, da voz, da articulação das palavras, dos pares cranianos.

\section{Psiquiátrica}

A avaliação deu-se através de entrevista utilizando uma ficha elaborada pelo psiquiatra Dr. Luiz Henrique Borges, a qual visava detectar sintomas relacionados ao quadro de eretismo psíquico que permitissem o estabelecimento de um diagnóstico diferencial em relação a outras patologias psiquiátricas.

\section{Psicológica}

$\mathrm{Na}$ avaliação psicológica, além da entrevista inicial, foram aplicados os seguintes testes neuropsicológicos, que são os mesmos previstos na Resolução no 307 da Secretaria de Estado de Saúde, de 14/08/91, publicada no Diário Oficial do Estado de São Paulo, seção I, em 15/08/91:

- Wechsler Memory Scale (David Wechsler e Calvin T. Stone), forma 1, traduzida e adaptada para o português (impresso fornecido pela psicóloga Beatriz Lefèvre). Os itens utilizados foram os seguintes: informação, orientação, controle mental, memória lógica, dígitos (ordem direta e ordem inversa), reprodução visual e aprendizagem por associação. Este teste permite avaliar as memórias de curto e longo prazos; alguns itens exigem também atenção. Existe uma correção para a idade. Ele fornece o quociente de memória (QM), cuja classificação adotada é:

- QM abaixo de 50, indicando distúrbio severo de memória;

- QM de 50 a 79, indicando dificuldade moderada;

- $\mathrm{QM}$ de 80 a 89, indicando dificuldade leve;

- QM de 90 a 109, indicando normalidade;

- QM de 110 e acima, indicando memória superior à média.

- Teste de Aptidão à Mecânica de Léon Walther (TAM) - Sub-Teste de Habilidade Manual. Os itens utilizados foram discos (Walther), contas (Descocudres) e pontilhagem (Binet e Vaschid). A finalidade do teste é a mensuração da rapidez de movimentos, da destreza manual, da coordenação mão/olho, da coordenação motora fina, da metodização e da sistematização ao realizar um trabalho. As normas deste teste foram feitas com trabalhadores industriais. A classificação é a seguinte:

- abaixo de P19, indicando dificuldade grave;

- de P20 a P30, indicando dificuldade moderada;

- de P31 a P49, indicando dificuldade leve;

- P50, indicando normalidade;

- acima de P50, indicando superioridade.

- Bateria Fatorial CEPA - Teste de Atenção Concentrada de Toulouse Pieron. O teste mede a rapidez gráfica e motora na execução de tarefa simples, de natureza perceptiva, e a exatidão com que a tarefa é executada. Fornece, portanto, duas medidas, $\mathrm{R}$ e $\mathrm{Q}$, ambas em percentil, sendo a classificação a seguinte:

- abaixo de P19, indicando dificuldade grave;

- de P20 a P30, indicando dificuldade moderada;

- de P31 a P49, indicando dificuldade leve;

- P50, indicando normalidade;

- acima de P50, indicando superior.

Com os resultados de todas as avaliações anteriormente citadas, cada caso foi discutido para o estabelecimento do diagnóstico. Não foi considerada, para fins diagnósticos, nenhuma avaliação isoladamente. 


\section{RESULTADOS E DISCUSSÃO}

\section{Visita à Fábrica}

A empresa contava, na época do estudo, com 641 trabalhadores, sendo 434 homens, 190 mulheres e 16 menores, perfazendo um total de 598 na produção e 43 na administração.

A produção ficava situada em um galpão industrial edificado com estrutura metálica (telhado) e concreto armado(pilares), com paredes de alvenaria e telhas de fibro-cimento. $\mathrm{O}$ piso era de cimento com acabamento liso. A iluminação artificial era feita à base de luminárias fluorescentes. Internamente, as linhas de produção delimitavam os setores, sendo circundadas por corredores de circulação que desembocavam nas principais saídas da fábrica.

Dos 598 trabalhadores da produção, 192 trabalhavam no setor de produção de lâmpadas fluorescentes.

Nesta empresa, o mercúrio metálico só era utilizado na fabricação de lâmpadas fluorescentes.

No setor fluorescente existiam duas linhas de produção de lâmpadas. Em cada linha havia uma máquina denominada pelos trabalhadores de exaustão, onde cerca de $800 \mathrm{cc}$ de mercúrio metálico eram distribuídos nas 48 bocas, ou dosadores. Eram consumidos, em média, $83 \mathrm{~kg}$ de mercúrio por mês. A carga completa de mercúrio era consumida em dois dias, sendo os dosadores recarregados pelos próprios trabalhadores. O mercúrio era injetado nos tubos de vácuo das lâmpadas através de dosadores.

Foram observados os seguintes riscos no setor fluorescente: ruído, calor, acidentes com partes móveis de máquinas, acidentes por corte com vidro, queimaduras causadas por vidro quente, lesões decorrentes de esforços repetitivos, intoxicação por chumbo e intoxicação por mercúrio metálico.

Os riscos detectados em outros setores não foram aqui mencionados por fugirem ao objetivo deste trabalho.

Foram observadas na área de produção: lâmpadas quebradas; presença de gotas de mercúrio no chão e nas máquinas; exaustão precária; mangueiras de ventilação soltas; máquinas com 12 a 20 anos de uso; calor em toda a área; favorecendo a rápida evaporação do mercúrio; laboratório em precárias condições; falta de filtros nas saídas de exaustão, lançando mercúrio no meio ambiente; e reaproveitamento dos tubos de lâmpadas parcialmente quebradas e contaminadas por mercúrio.

Houve informação de que são produzidas, em média, 10.000 lâmpadas por dia, com quebra de aproximadamente $10 \%$ deste total.

A limpeza do chão, das máquinas e das peças era realizada pelos próprios trabalhadores.

A quebra das lâmpadas que apresentavam defeitos era feita na área, dentro de um recipiente seco (tonel com capacidade para cerca de 10 litros).

A avaliação ambiental realizada pela empresa mostrou a) calor variando de 17,00 a 30,95 IBUTG; e b) mercúrio ambiental $0,00 \mathrm{mg} / \mathrm{m} 3$ ou traços indosáveis.

As avaliações efetuadas não mencionavam a metodologia utilizada, aparelho, local, horário e duração da medição.

De acordo com o parecer técnico da Fundação Jorge Duprat Figueiredo (Fundacentro), dos pontos de vista químico e analítico e da significância para avaliar os níveis de exposição ocupacional ao mercúrio, os dados apresentados pela empresa não têm validade.

Não foram feitas mudanças ambientais durante o período em que se realizaram as visitas.

\section{Grupos de Trabalhadores}

Foram realizadas reuniões quinzenais, nas quais os trabalhadores formularam os cinco grupos de risco.

No grupo 1 (cargas físicas) foram levantados ruído (principalmente na sala de máquinas e bico de ar); calor; vibração (principalmente nos compressores e máquinas do setor fluorescente); luminosidade (lâmpadas acendendo e apagando nas máquinas onde são feitos testes de qualidade).

No grupo 2 (cargas químicas) foram levantados mercúrio (principalmente no laboratório químico e setor de produção de lâmpadas fluorescentes); fósforo (no setor de revestimento de lâmpadas); querosene; álcool; silicone; amoníaco; resina fenólica; xilol; butanol; chumbo; entre outros.

No grupo 3 (cargas fisiológicas) foram levantados esforço físico (na colocação de lâmpadas 
na baseadora manual, no setor de embalagem onde são transportados estrados, no transporte de tambores de vidro, no transporte de carrinhos, na utilização da escada que passa por cima da linha fluorescente); posições incômodas (do mecânico embaixo da máquina, do operador da máquina de exaustão quando se senta na cadeira com altura inadequada). Foram discutidos, ainda, a inadequação, a baixa qualidade e o desconforto dos equipamentos de proteção individual.

No grupo 4 (cargas psíquicas) foram levantados a jornada excessiva de trabalho (48 horas); o horário insuficiente para almoço (30 minutos); as pausas curtas e nem sempre respeitadas (10 minutos para café e 10 minutos para uso do banheiro); a inexistência de proteção na selagem; o lidar constante com as emergências (reserva de linha e mecânico de linha); o ritmo de trabalho de acordo com a cadência da máquina; a necessidade de atenção constante por parte de todos; a monotonia na linha; a impossibilidade de conversar com colegas; a ameaça de redução de salário e demissões; o desvio da função registrada na Carteira de Trabalho; o desconhecimento dos critérios de avaliação de desempenho e promoção; a agressividade e a cobrança por parte da chefia; a obrigatoriedade de lavar os próprios uniformes em casa (inclusive os contaminados por mercúrio e/ou outros agentes tóxicos); a falta de higiene no refeitório e banheiros; a falta de calçados adequados.

No grupo 5 (cargas mecânicas) foram levantados pontas e cacos de vidro; manipulação de lâmpadas quentes; trânsito interno da empilhadeira; piso irregular; ferramentas em mau estado de conservação; queimaduras produzidas por respingos de mercúrio quente.

Foi elaborado o mapa de risco. O processo produtivo na linha fluorescente foi representado graficamente, tendo sido colocados os seguintes riscos em cada máquina da linha: no forno Becker foram apontados o gás $\mathrm{SO}_{2}$ e o calor; na selagem foram apontados nitrogênio, calor e falta de proteção na máquina; na exaustão foram descritos gases, calor, ruído, piso escorregadio, cadeira de altura inadequada, respingos quentes de mercúrio; no threading foram mencionados o calor e o mercúrio; na máquina baseadora foram levantados o calor, o ruído, a luminosidade excessiva e o mercúrio; no setor de embalagem, o principal item mencionado foi o esforço físico. Ritmo de trabalho acelerado, pontas de vidro e lâmpadas quentes, segundo os trabalhadores, existiam em toda a linha, bem como o ruído.

Os autores realizaram palestras e orientações sobre os riscos levantados, conforme solicitação dos trabalhadores. O grupo atuou também como fonte de apoio sócio-emocional para os trabalhadores.

\section{Avaliação dos Trabalhadores}

Dos 91 trabalhadores avaliados, $83(91,21 \%)$ eram do sexo masculino e $8(8,79 \%)$ eram do feminino, não havendo nenhum analfabeto (Tabela 1).

TABELA 1. Distribuição do Número e Percentagem de Trabalhadores Expostos ao Mercúrio Metálico, Segundo Nível de Instrução. Indústria de Lâmpadas Elétricas, Santo Amaro, São Paulo, 1992

\begin{tabular}{llc}
\hline \hline Nível de Instrução & № & $\%$ \\
\hline Analfabeto & - & - \\
1 Grau Incompleto & 56 & 61,54 \\
1 Grau Completo $^{\circ}$ & 20 & 21,98 \\
$2^{\circ}$ Grau Incompleto & 09 & 9,89 \\
$2^{\circ}$ Grau Completo & 02 & 2,20 \\
Superior & - & - \\
Sem Informação & 04 & 4,39 \\
\hline Total & 91 & 100,00 \\
\hline \hline
\end{tabular}

As idades variaram de 20 a 65 anos, sendo que $60(65,93 \%)$ situavam-se na faixa de 20 a 35 anos. Nesta faixa, $50(54,94 \%)$ estavam intoxicados (Tabela 2).

Os trabalhadores estudados estavam distribuídos nas seguintes funções: mecânico de manutenção, ajudante de produção, operador de máquina, eletricista de manutenção, lubrificador, operador de embalagem, revestidor químico, operador de empilhadeira, recuperador, inspetor de breakdown, operador de materiais e faxineira (Tabela 3 ).

O tempo de exposição variou de 4 meses a 30 anos, sendo que com tempo de exposição até 3 anos foram encontrados 38 na faixa trabalhadores intoxicados $(49,35 \%)$ (Tabela 4$)$. 
TABELA 2. Distribuição do Número e Percentagem de Trabalhadores Expostos ao Mercúrio Metálico, segundo Idade e Presença ou Ausência de Intoxicação. Indústria de Lâmpadas Elétricas, Santo Amaro, São Paulo, 1992

\begin{tabular}{|c|c|c|c|c|c|c|c|c|}
\hline \multirow{2}{*}{$\begin{array}{l}\text { Idade } \\
\text { (em anos) }\end{array}$} & \multicolumn{2}{|c|}{ Intoxicados } & \multicolumn{2}{|c|}{ Não Intoxicados } & \multicolumn{2}{|c|}{ Inconclusivos } & \multicolumn{2}{|c|}{ Total } \\
\hline & № & $\%$ & № & $\%$ & № & $\%$ & № & $\%$ \\
\hline $20-25$ & 19 & 20,88 & 3 & 3,30 & 2 & 2,20 & 24 & 26,38 \\
\hline $26-30$ & 12 & 13,19 & 1 & 1,09 & - & - & 13 & 14,28 \\
\hline $31-35$ & 19 & 20,88 & 2 & 2,20 & 2 & 2,20 & 23 & 25,28 \\
\hline $36-40$ & 9 & 9,90 & 1 & 1,09 & - & - & 10 & 10,99 \\
\hline $41-45$ & 10 & 10,99 & - & - & - & - & 10 & 10,99 \\
\hline $46-50$ & 4 & 4,40 & 2 & 2,20 & - & - & 6 & 6,60 \\
\hline $51-55$ & 3 & 3,30 & - & - & - & - & 3 & 3,30 \\
\hline $56-60$ & 一 & - & 1 & 1,09 & - & - & 1 & 1,09 \\
\hline $61-65$ & 1 & 1,09 & - & 一 & - & 一 & 1 & 1,00 \\
\hline Total & 77 & 84,63 & 10 & 10,97 & 4 & 4,40 & 91 & 100,00 \\
\hline
\end{tabular}

TABELA 3. Distribuição do Número e Percentagem de Trabalhadores Expostos ao Mercúrio Metálico, segundo Presença ou Não de Intoxicação e Cargo/Função Exercido. Indústria de Lâmpadas Elétricas, Santo Amaro, São Paulo, 1992

\begin{tabular}{lrrrrcccc}
\hline \hline \multirow{2}{*}{ Cargo/Função } & \multicolumn{2}{c}{ Intoxicados } & \multicolumn{2}{c}{ Não Intoxicados } & \multicolumn{2}{c}{ Inconclusivos } & \multicolumn{2}{c}{ Total } \\
& № & \multicolumn{1}{c}{$\%$} & № & $\%$ & № & $\%$ & № & $\%$ \\
\hline Mecânico Manut. & 23 & 85,19 & 3 & 11,11 & 1 & 3,70 & 27 & 100,00 \\
Ajudante Prod. & 22 & 78,57 & 4 & 14,29 & - & 7,14 & 28 & 100,00 \\
Operador Máqu. & 19 & 100,00 & - & - & 2 & - & 19 & 100,00 \\
Eletric. Manut. & 2 & 50,00 & 2 & 50,00 & - & - & 4 & 100,00 \\
Lubrificador & 2 & 66,67 & 1 & 33,33 & - & - & 3 & 100,00 \\
Operador Embal. & 1 & 100,00 & - & - & - & - & 1 & 100,00 \\
Revestid. Quím. & 1 & 100,00 & - & - & - & - & 1 & 100,00 \\
Operador Empilh. & 2 & 100,00 & - & - & - & - & 2 & 100,00 \\
Recuperador & - & - & - & - & 1 & 100,00 & 1 & 100,00 \\
Inspet. Breakdown & 1 & 100,00 & - & - & - & - & 1 & 100,00 \\
Operador Mater. & 3 & 100,00 & - & - & - & - & 3 & 100,00 \\
Faxineira & 1 & 100,00 & - & - & - & - & 1 & 100,00 \\
\hline Total & 77 & 84,62 & 10 & 10,99 & 4 & 4,39 & 91 & 100,00 \\
\hline \hline
\end{tabular}

TABELA 4. Distribuição do Número e Percentagem de Trabalhadores Expostos ao Mercúrio Metálico, segundo Tempo de Exposição e Presença ou Não de Intoxicação. Indústria de Lâmpadas Elétricas, Santo Amaro, São Paulo, 1992

\begin{tabular}{|c|c|c|c|c|c|c|c|c|}
\hline \multirow{2}{*}{$\begin{array}{l}\text { Tempo de Exposição } \\
\text { (em anos) }\end{array}$} & \multicolumn{2}{|c|}{ Intoxicados } & \multicolumn{2}{|c|}{ Não Intoxicados } & \multicolumn{2}{|c|}{ Inconclusivos } & \multicolumn{2}{|c|}{ Total } \\
\hline & № & $\%$ & № & $\%$ & № & $\%$ & № & $\%$ \\
\hline Menos de 1 & 7 & 70,00 & 2 & 20,00 & 1 & 10,00 & 10 & 100,00 \\
\hline $1-3$ & 31 & 86,11 & 3 & 8,33 & 2 & 5,56 & 36 & 100,00 \\
\hline $4-6$ & 19 & 85,00 & 2 & 10,00 & 1 & 5,00 & 22 & 100,00 \\
\hline $7-9$ & 5 & 100,00 & - & - & - & - & 5 & 100,00 \\
\hline $10-12$ & 7 & 77,78 & 2 & 22,22 & - & - & 9 & 100,00 \\
\hline $13-15$ & 4 & 100,00 & - & - & - & - & 4 & 100,00 \\
\hline $16-18$ & 1 & 50,00 & 1 & 50,00 & - & - & 2 & 100,00 \\
\hline $19-21$ & 1 & 100,00 & - & - & - & - & 1 & 100,00 \\
\hline $22-24$ & 1 & 100,00 & - & - & - & - & 1 & 100,00 \\
\hline Acima de 24 & 1 & 100,00 & - & - & - & - & 1 & 100,00 \\
\hline Total & 77 & 84,89 & 10 & 10,46 & 4 & 4,65 & 91 & 100,00 \\
\hline
\end{tabular}


Os sintomas referidos foram agrupados nas síndromes gastrintestinal, neurológica, eretismo psíquico e outros sintomas. Na sintomatologia gastrintestinal destacaram-se a epigastralgia $(63,73 \%)$, digestão difícil $(53,84 \%)$, gosto metálico $(52,74 \%)$. Na sintomatologia neurológica predominaram a cefaléia $(79,12 \%)$, parestesia $(56,04 \%)$, insônia $(52,74 \%)$ e tremores $(50,54 \%)$. No eretismo psíquico os sintomas mais referidos foram nervosismo $(72,52 \%)$, irritabilidade $(68,13 \%)$, distúrbios de memória $(50,54 \%)$ e tristeza $(39,56 \%)$. Em outros sinto- mas foram encontrados irritação nos olhos $(64,83 \%)$, fraqueza muscular $(61,53 \%)$ e borramento visual $(48,35 \%)$ (Tabela 5).

Dos sinais detectados no exame clínico-neurológico, os mais importantes na caracterização do quadro da intoxicação crônica por mercúrio metálico foram os tremores $(75,82 \%)$ e as alterações de cavidade oral (faringite) $(51,65 \%)$, linha azul na margem alveolar (17,58\%), depósitos gengivais $(8,79 \%)$ e ulcerações orais $(8,79 \%)$. Ocorreu ainda hipertensão arterial $(54,95 \%)$ (Tabela 6).

TABELA 5. Distribuição do Número e Percentagem de Trabalhadores Expostos ao Mercúrio Metálico, segundo Sintomatologia Referida. Indústria de Lâmpadas Elétricas, Santo Amaro, SP, 1992

\begin{tabular}{|c|c|c|c|}
\hline \multirow{2}{*}{$\begin{array}{l}\text { Gastrintestinal } \\
\text { Sintomas Referidos }\end{array}$} & \multirow[b]{2}{*}{ № } & \multicolumn{2}{|l|}{ Neurológico } \\
\hline & & Sintomas Referidos & № \\
\hline Epigastralgia & 58 & Cefaléia & 72 \\
\hline Digestão Difícil & 49 & Parestesia & 51 \\
\hline Gosto Metálico & 48 & Insônia & 48 \\
\hline Sialorréia & 46 & Tremores & 46 \\
\hline Náuseas & 38 & Sonolência & 34 \\
\hline Sangramento Oral & 37 & Câimbras & 27 \\
\hline Gengivite & 35 & Alteração de Grafia & 17 \\
\hline Cólicas Intestinais & 34 & Gritos Noturnos & 10 \\
\hline Ulcerações Orais & 31 & Abalos Tônico-Clôn. & 9 \\
\hline Diarréia & 29 & Dificuld. Equilíbrio & 7 \\
\hline Amolecimento de Dentes & 16 & Tontura & 4 \\
\hline Obstipação Intestinal & 15 & & \\
\hline Melena & 13 & & \\
\hline Hematemese & 4 & & \\
\hline Sangramento Retal & 4 & & \\
\hline Eretismo Psiquíco & & Outros & \\
\hline Sintomas Referidos & № & Sintomas Referidos & № \\
\hline Nervosismo & 66 & Irritação nos Olhos & 59 \\
\hline Irritabilidade & 62 & Fraqueza Muscular & 56 \\
\hline Distúrbios de Memória & 46 & Borramento Visual & 44 \\
\hline Tristeza & 36 & Zumbido & 29 \\
\hline Diminuição da Atenção & 30 & Irritação Nasal & 29 \\
\hline Depressão & 30 & Diminuição da Visão & 26 \\
\hline Agressividade & 29 & Diminuição da Audição & 24 \\
\hline Insegurança & 25 & Dor Torácica & 23 \\
\hline Medo & 23 & Impotência Sexual & 18 \\
\hline Ansiedade & 23 & Disúria & 18 \\
\hline Vontade de Morrer & 11 & Tosse & 11 \\
\hline \multirow[t]{7}{*}{ Perda da Iniciativa } & 2 & Dispnéia & 8 \\
\hline & & Sangramento Nasal & 4 \\
\hline & & Dor Muscular & 4 \\
\hline & & Diplopia & 3 \\
\hline & & Hematúria & 2 \\
\hline & & Alterações Cutâneas & 2 \\
\hline & & Dor de Ouvido & 2 \\
\hline
\end{tabular}


TABELA 6. Distribuição do Número e Percentagem de Trabalhadores Expostos ao Mercúrio Metálico, segundo Sinais Detectados no Exame Clínico-Neurológico. Indústria de Lâmpadas Elétricas, Santo Amaro, São Paulo, 1992

\begin{tabular}{lcc}
\hline \hline Sinais Detectados & № & $\%$ \\
\hline Tremores & 69 & 75,82 \\
Hipertensão Arterial & 50 & 54,95 \\
Faringite & 47 & 51,65 \\
Amigdalite & 43 & 47,25 \\
Conjuntivite & 35 & 38,46 \\
Hepatomegalia & 20 & 21,98 \\
Linha Azul na Margem Alveolar & 16 & 17,58 \\
Arritmia Cardíaca & 14 & 15,38 \\
Edema de Membros Inferiores & 14 & 15,38 \\
Sopro Sistológico de Foco Mitral & 12 & 13,19 \\
Depósitos Gengivais & 8 & 8,79 \\
Ulcerações Orais & 8 & 8,79 \\
Auscuta Pulmonar Alterada & 5 & 5,49 \\
Dor à Palpação da Região Epigástrica & 4 & 4,40 \\
Alterações Cutâneas & 4 & 4,40 \\
Alterações de Sensibilidade & 2 & 2,20 \\
Nistagmo Multidirecional Bilateral & 1 & 1,09 \\
Espondilite Anquilosante & 1 & 1,09 \\
Extração Renal & 1 & 1,09 \\
Punho Percussão Positiva & 1 & 1,09 \\
Dentes Moles & 1 & 1,09 \\
Alterações de Reflexos & 1 & 1,09 \\
Edema Gengival & 1 & 1,09 \\
\hline \hline
\end{tabular}

Os exames complementares efetuados revelaram os seguintes resultados:

a) mercúrio urinário: 23 dos trabalhadores $(11,97 \%)$ apresentaram mercúrio urinário abaixo de $10 \mathrm{~g} / \mathrm{l}, 100$ (52,08\%) entre $10 \mathrm{e}$ $50 \mathrm{~g} / \mathrm{l}, 27$ (14,06\%) acima de $50 \mathrm{~g} / \mathrm{l}$ e 42 sem informação (Tabela 7);

b) elementos anormais e sedimentos urinários: foi encontrada proteinúria em 9 casos, hematúria em 3 e leucocitúria em 2 casos, sendo que os demais não apresentaram alterações;

c) colesterol: os resultados foram elevados em 4 casos;

d) função hepática: transaminase oxalacética elevada em 3 casos, transaminase glutâmica pirúvica elevada em 2 casos e fosfatase alcalina elevada em 1 caso;

e) hemograma: anemia em 1, leucocitose em 16, leucopenia em 6, linfocitose em 6 , eosinofilia em 5, neutrofilia em 4 e atipia linfocitária em 3;
TA BE LA 7. Distribuição do Número e Percentagem de Trabalhadores do Setor de Lâmpadas Fluoresecentes Expostos ao Mercúrio Metálico, segundo o Resultado de Dosagem de Mercúrio Urinário. Indústria de Lâmpadas Elétricas, Santo Amaro, São Paulo, 1992

\begin{tabular}{lcc}
\hline \hline Resultado de $\mathrm{HgU}$ & № & $\%$ \\
\hline Abaixo de $10 \mu \mathrm{g} / 1$ & 23 & 11,97 \\
$10-19 \mu \mathrm{g} / 1$ & 36 & 18,75 \\
$20-29 \mu \mathrm{g} / 1$ & 32 & 16,66 \\
$30-39 \mu \mathrm{g} / 1$ & 17 & 8,85 \\
$40-49 \mu \mathrm{g} / 1$ & 15 & 7,82 \\
50 e acima & 27 & 14,06 \\
Sem Informação & 42 & 21,87 \\
\hline Total & 192 & 100,00 \\
\hline \hline
\end{tabular}

f) função renal: uréia elevada em 4 casos e creatinina elevada em 2;

g) eletromiografia: 1 caso de neuropatia periférica; 
h) Tomografia computadorizada cerebral: 1 caso de calcificação cerebral;

i) endoscopia: gastrite em 3 casos, úlcera gástrica em 1 e duodenal em 1;

j) audiometria tonal: 42 estavam dentro da normalidade, 32 apresentaram disacusia neurossensorial e 17 não realizaram o exame.

Os resultados dos testes neuropsicológicos realizados para a verificação da memória, função motora e atenção concentrada foram os seguintes:

a) memória: foram encontrados 72 casos $(79,12 \%)$ com distúrbios de memória variando de discretos (20) a moderados (52). Não foram detectados distúrbios graves e apenas 15 trabalhadores $(16,48 \%)$ apresentaram resultados dentro da normalidade;

b) função motora: os prejuízos maiores ocorreram em relação ao item pontilhagem, que consiste em fazer um ponto em cada quadrado o mais rapidamente possível, tendo por finalidade a mensuração da rapidez gráfica e motora, item em que 66 trabalhadores $(72,53 \%)$ apresentaram dificuldades graves. No item discos, que consiste em passar pequenos discos redondos de um tabuleiro contendo orifícios mais rasos para outro contendo orifícios mais profundos, com a mão direita, com a mão esquerda e depois com ambas as mãos, tendo por finalidade a mensuração da destreza manual, coordenação mão/olho, além da metodização, ocorreram 54 casos $(59,93 \%)$ com dificuldade variando de leve a grave. Em contas, que consiste na colocação de pequenas contas em um fio e mede a coordenação motora fina, tivemos 46 $(50,55 \%)$ com dificuldade variando de leve a grave.

c) Atenção: com relação à rapidez gráficomotora tivemos 59 trabalhadores com resultados deficientes $(64,84 \%)$, sendo que, algumas vezes, os trabalhadores que apresentavam pouca rapidez mostravam melhor qualidade, o que significa que o trabalhador, ao executar a tarefa lentamente, consegue prestar atenção, evitando, assim, erros e omissões. Tivemos outros trabalhadores com grande rapidez, mas pouca qualidade. Em relação à qualidade, tivemos 66 trabalhadores $(72,53 \%)$ com resultados deficientes (Tabela 8).

TABELA 8. Distribuição do Número e Percentagem de Trabalhadores Expostos ao Mercúrio Metálico, segundo Resultados dos Testes Neuropsicológicos. Indústria de Lâmpadas Elétricas, Santo Amaro, São Paulo, 1992

\begin{tabular}{|c|c|c|c|c|c|c|}
\hline \multirow{3}{*}{$\begin{array}{l}\text { Testes } \\
\text { Resultados }\end{array}$} & \multicolumn{2}{|c|}{ Memória (WMS) } & \multicolumn{4}{|c|}{ Atenção (A C) } \\
\hline & \multirow[b]{2}{*}{$\mathrm{N}$} & \multirow[b]{2}{*}{$\%$} & \multicolumn{2}{|c|}{ Rapidez } & \multicolumn{2}{|c|}{ Qualidade } \\
\hline & & & $\mathrm{N}$ & $\%$ & $\mathrm{~N}$ & $\%$ \\
\hline Superior & 3 & 3,29 & 27 & 29,67 & 17 & 18,68 \\
\hline Média & 15 & 16,48 & 3 & 3,30 & 6 & 6,59 \\
\hline Dific. Leve & 20 & 21,99 & 16 & 15,58 & 16 & 17,58 \\
\hline Dific. Moder. & 52 & 57,15 & 14 & 15,38 & 15 & 16,48 \\
\hline Dific. Grave & - & - & 29 & 31,87 & 35 & 38,47 \\
\hline Não Realizado & 1 & 1,09 & 2 & 2,20 & 2 & 2,20 \\
\hline $\begin{array}{l}\text { Total }=-\mathbf{-}=- \\
\text { Testes }\end{array}$ & 91 & 100,00 & unçãc & $\begin{array}{l}100,00 \\
0(\mathrm{TAM}) \\
\end{array}$ & 91 & 100,00 \\
\hline \multirow[t]{2}{*}{ Resultados } & \multicolumn{2}{|c|}{ Discos } & \multicolumn{2}{|c|}{ Contas } & \multicolumn{2}{|c|}{ Pontilhagem } \\
\hline & $\mathrm{N}$ & $\%$ & $\mathrm{~N}$ & $\%$ & $\mathrm{~N}$ & $\%$ \\
\hline Superior & 32 & 35,16 & 40 & 43,96 & 7 & 7,69 \\
\hline Média & 3 & 3,30 & 3 & 3,30 & 1 & 1,09 \\
\hline Dific. Leve & 11 & 12,09 & 9 & 9,89 & 4 & 4,40 \\
\hline Dific. Moderada & 14 & 15,38 & 15 & 16,48 & 11 & 12,09 \\
\hline Dific. Grave & 29 & 31,87 & 22 & 24,17 & 66 & 72,53 \\
\hline Não Realizado & 2 & 2,20 & 2 & 2,20 & 2 & 2,20 \\
\hline Total & 91 & 100,00 & 91 & 100,00 & 91 & 100,00 \\
\hline
\end{tabular}


Para a caracterização do quadro da intoxicação de cada trabalhador, foi levado em consideração o somatório das alterações apresentadas em cada clínica (médica, neurológica, psicológica e psiquiátrica), associadas entre si e compa- radas com a literatura internacional.

Em 45 casos $(58,44 \%)$ ocorreram alterações em todas as clínicas e em $65(84,41 \%)$ ocorreram alterações em no mínimo 3 das clínicas (Tabela 9).

TABELA 9. Distribuição do Número e Percentagem de Trabalhadores Expostos ao Mercúrio Metálico, segundo a Combinação do Conjunto de Alterações Apresentadas nos Exames Clínico, Neurológico, Psiquiátrico e Psicológico. Indústria de Lâmpadas Elétricas, Santo Amaro, São Paulo, 1992

\begin{tabular}{lcc}
\hline \hline Alterações Combinadas aos Exames & \multicolumn{2}{c}{ Trabalhadores } \\
& № & $\%$ \\
\hline Clínico, Neurológico, Psiquiátrico, Psicológico & 45 & 58,44 \\
Clínico, Neurológico, Psicológico & 9 & 11,69 \\
Neurológico, Psiquiátrico, Psicológico & 7 & 9,09 \\
Neurológico, Psicológico & 6 & 7,79 \\
Clínico, Psiquiátrico, Psicológico & 4 & 5,19 \\
Psiquiátrico, Psicológico & 3 & 3,90 \\
Clínico, Psicológico & 2 & 2,60 \\
Clínico, Neurológico & 1 & 1,30 \\
\hline Total & 77 & 100,00 \\
\hline \hline
\end{tabular}

\section{CONCLUSÕES}

O número de trabalhadores intoxicados foi de $77(84,62 \%)$, o que aponta para a gravidade do problema, em virtude da natureza da doença, que compromete áreas nobres do organismo; do acometimento de trabalhadores jovens; e da ineficácia dos tratamentos existentes.

Tendo em vista a gravidade da intoxicação por mercúrio e o fato de, no ambiente de trabalho da população estudada, ocorrer a exposição combinada e simultânea a vários riscos, assim como na maioria dos ambientes de trabalho, achamos que esta população deve ser objeto de maiores e mais aprofundadas investigações científicas.

Estas investigações devem ter como objetivos principais o seguimento continuado e permanente destes trabalhadores, principalmente por causa da irreversibilidade dos danos apresentados em muitos casos de intoxicação mercurial; a definição de metodologias que permitam uma avaliação do peso que cada um dos riscos tem no quadro da intoxicação por mercúrio; e finalmente, e mais importante, a definição de programas mais eficazes de prevenção.
Dada a importância de um diagnóstico correto, além de exames completos e detalhados, é importante que sejam obtidas informações acuradas sobre o ambiente de trabalho. Para tanto, é desejável que possam ser feitas visitas ao mesmo, tantas vezes quantas forem necessárias. Além das visitas, as informações que podem ser obtidas através dos grupos de trabalhadores são de grande riqueza e importância para que se tenha um quadro claro da situação de trabalho. Por outro lado, elas permitem que os trabalhadores não só obtenham informações sobre os riscos à saúde representados pelos agentes tóxicos presentes no ambiente de trabalho, mas também possam compreender melhor o próprio trabalho e o processo produtivo como um todo dotado de sentido. 


\section{RESUMO}

\section{ZAVARIZ, C. \& GLINA, D. M. R. Efeitos} da Exposição Ocupacional ao Mercúrio em Trabalhadores de uma Indústria de Lâmpadas Elétricas Localizada em Santo Amaro, São Paulo, Brasil. Cad. Saúde Públ., Rio de Janeiro, 9 (2): 117-129, abr/jun, 1993.

O presente estudo teve como objetivo verificar a intoxicação por mercúrio metálico em trabalhadores de uma indústria de lâmpadas elétricas situada em Santo Amaro, São Paulo. Foram realizadas visitas à empresa para verificação do ambiente e das condições de trabalho, além de reuniões com os trabalhadores para uma melhor compreensão acerca do processo produtivo e de suas repercussões na saúde. Foram investigados 91 trabalhadores, dos quais $77(84,62 \%)$ apresentaram quadro de intoxicação crônica. Entre os intoxicados, foram detectadas alterações nos testes neuropsicológicos em 76 $(98,70 \%)$, alterações neurológicas em 69 $(75,82 \%)$, alterações no exame clínico em 62 $(68,13 \%)$ e alterações psiquiátricas em 59 $(63,96 \%)$.

Palavras-Chave: Exposição Ocupacional; Efeitos Adversos; Mercúrio; Toxicologia Industrial

\section{REFERÊNCIAS BIBLIOGRÁFICAS}

ALONSO, F. F., 1972. Fundamentos da Psiquiatria A tual. Espanha: Paz Montalvo.

ANGOTZI, G.; CASSITO, M. G.; CAMERINO, D.; CIONE, R.; DESIDERI, E. FRANZINELLI, A.; GORI, R.; LOI, F. \& SANTORELLI, E., 1980. Rapporti tra esposizione a mercurio e condizione di salutte in un grupo di lavoratori addeti alladistillazione di mercurio in uno stabilimento della provincia di Siena. La M edicina del Lavoro, 71: 463-480.

ENCYCLOPAEDIA OF OCCUPATIONAL

HEALTH AND SAFETY, 1989. vol. 2, Geneva: International Labour Office, pp. 1334-1340.

FOÁ, V. \& CAIMI, L., 1981. Patologia del mercurio e suoi composti. In: Tratatto di Medicina del Lavoro (E. Sartorelli), pp. 353-376, Padova: Piccin.
FOÁ, V., 1985. Neurotoxicology of elemental mercury. In: Neurotoxicology (B. Kenneth \& L. Manzol), pp. 353-376, New York: Marcel Dekker inc.

FOÁ, V. \& BERTELLI, G., 1986. Mercury. In: Biological Indicators for the Assessment of Human Exposure to Industrial Chemicals (L. Alessio; A. Berlin; M. Boni \& R. Roi), pp. 32-46, Luxemburgo: Official Publications of European Communities.

GALVÃO, A. C. L. \& COREY, G., 1987. Mercúrio. Série Vigilância, 7: 1-82, México, Organización Panamericana de la Salud e Organización Mundial de la Salud.

HANNINEN, H., 1982. Behavioral effects of occupational exposure to mercury and lead. Acta Neurologica Scandinavica, 92: 167-175.

HARTMAN, D., 1988. Neuropsychological Toxicology: Identification and Assessment of Human Neurotoxic Syndromes. New York: Pergamon Press.

LANGOLF, G. D.; CHAFFIN, D. B.; HENDERSON, R. \& WHITTLE, H. P., 1978. Evaluation of workers exposed to elemental mercury using quantitative tests of tremor and neuromuscular functions. American Industrial Hygiene Association J ournal, 39: 976-984.

LAURELL, A. C. \& NORIEGA, M., 1989. Processo de Produção e Saúde: Trabalho e Desgaste Operário. São Paulo: Hucitec.

OCCUPATIONAL HEALTH GUIDELINES FOR CHEMICAL HAZZARDS, 1981. Vol. 3, Washington: National Institute for Occupational Safety and Health.

ODDONE, I.; GASTONE, M.; GLORIA, S.; BRIANTE, G. \& CHIATELLA, M., 1986. Ambiente de Trabalho: a Luta dos Trabalhadores pela Saúde. São Paulo: Hucitec.

PIIKIVI, L.; HANNINEN, H.; MARTELIN, T.; MANTERE, P., 1984. Psychological performance and long-term exposure to mercury vapors. Scandinavian Journal of Work Environmental Health, 10: 35-41.

SMITH, P. J.; LANGLOF, G. D. \& GOLDBERG, J., 1983. Effects of occupational exposure to elemental mercury on short-term memory. British Journal of Industrial Medicine, 40: 412-419.

VROOM, F. \& GREER, M., 1972. Mercury vapor intoxication. Brain, 95: 305-312.

World Health Organisation (WHO), 1991. Environmental Health Criteria 118: Inorganic Mercury. Genebra: World Health Organisation. 